\title{
SPATIAL DIFFERENTIATION IN INDUSTRIAL DYNAMICS. THE CASE OF THE NETHERLANDS (1994-2005)
}

\author{
MARCO CAPASSO*, ELENA CEFIS** \& KOEN FRENKEN*** \\ *Department of Economics, Maastricht University, Maastricht, the Netherlands. E-mail: \\ marco.capasso@gmail.com \\ **Department of Management, Economics and Quantitative Methods, University of Bergamo, Bergamo, \\ Italy.E-mail: elena.cefis@gmail.com \\ *** (Corresponding author) Innovation Studies, Copernicus Institute of Sustainable Development, Utrecht \\ University, Utrecht, the Netherlands and CIRCLE, Lund University, Sweden. E-mail: k.frenken@uu.nl
}

Received: April 2013; accepted January 2015

\begin{abstract}
We compare the industrial dynamics in the core, semi-periphery and periphery in the Netherlands in terms of firm entry-exit, size, growth and location patterns. The contribution of our work is to provide the first comprehensive study on spatial differentiation in industrial dynamics for all firm sizes and all sectors, including services. We find that location patterns are largely consistent with the spatial product lifecycle model: traditional Fordist sectors are overrepresented in the periphery, while sectors associated with the ICT paradigm are overrepresented in the core, with the notable exception of science-based manufacturing. Second, where the industrial dynamics in manufacturing sectors follow the predicted patterns, the industrial dynamics in service sectors largely contradict product lifecycle theory. We conclude that the spatial product lifecycle theory applies well to traditional manufacturing, while more specific theories are required to understand the location and industrial dynamics of sciencebased industries and service industries.
\end{abstract}

Key words: Firm location, firm size, entry, exit, spatial product lifecycle, the Netherlands

\section{INTRODUCTION}

It is well known that industrial dynamics are sector-specific (Gort \& Klepper 1982; Malerba \& Orsenigo 1996; Marsili 2001; Bottazzi et al. 2007), but less is known about their spatial differentiation (for reviews, Van Oort et al. 2012; Frenken et al. 2015). Industrial dynamics patterns such as entry, exit and growth may differ across regions, at both the aggregate and sectoral levels. Such differences are generally associated with technological dynamics, with the more densely populated 'core' being specialised in more innovative manufacturing and service sectors, and the periphery in more tra- ditional production-oriented sectors (where core and periphery are defined in terms of the population or job density).

Inspired by Castellacci's (2008) classification of sectors into the Fordist and information and communication technology (ICT) paradigm, we analyse whether the sectoral specialisation patterns differ systematically across Fordist and ICT-related sectors. In particular, we provide a new test of the spatial product lifecycle approach in economic geography, which hypothesises that sectors with many products in the early stages of their lifecycles (here, ICT) are over-represented in the core area while those sectors with many products in the later 
stages of their lifecycles (here Fordist) are overrepresented in the periphery (Thompson 1968; Duranton \& Puga 2001). We will also analyse whether the industrial dynamics - in terms of entry, exit, size and growth - are different in the core and periphery as predicted by the spatial product lifecycle. In all analyses, we do not only take into account core and periphery, but also the intermediate zone between core and periphery, otherwise known as semi-periphery.

Our study is unique in using data on firms of all sizes and all sectors and for an extended period (1994-2005). This allows us to closely follow Castellacci's (2008) taxonomy of sectors belonging to either the Fordist or the ICT paradigm, which includes both manufacturing and service sectors (knowledge-intensive business services and information network services for the ICT paradigm, and physical network services for the Fordist paradigm). By doing so, we can analyse whether the service sectors, in each of the two paradigms, display the same industrial dynamics as their manufacturing counterparts. To this end, we will first reflect in the theoretical part on the question whether the spatial product lifecycle, which was originally conceived only for manufacturing sectors, is expected to apply to service sectors as well.

We present two main findings. First, with the exception of the science-based industries, the spatial product lifecycle (PLC) well explains the sectoral location patterns in the core, semiperiphery and periphery, with ICT-related sectors being specialised in the core and Fordist sectors in the periphery. Second, the industrial dynamics in manufacturing, except for sciencebased industries, follow the main predictions of the spatial PLC model (entry and exit are higher in the core than in the periphery, and growth rates are higher in the periphery than in the core). However, service sectors do not follow all the patterns in industrial dynamics as predicted by the PLC theory.

\section{SPATIAL PRODUCT LIFE GYCLE THEORY}

The product lifecycle (PLC) is a very well established concept in industrial dynamics, dating back to the seminal work by Levitt
(1965) in management, Vernon (1966) in international trade and Utterback and Abernathy (1975) in industrial organisation. The notion of a lifecycle suggests that industries typically evolve in particular stages. In the explorative stage of an industry, entrepreneurs pursue commercial opportunities based on new products resulting from product innovation. At this stage, the technological possibilities and preferences of consumers are still poorly understood by firms. Progressive standardisation of product designs triggers process innovation and this marks the transition from the explorative stage to the mature stage in the PLC. The mature stage is exhausted when technological and market opportunities become depleted and decreasing returns to R\&D set in.

The patterns of innovative activity in the PLC have important consequences for industrial dynamics. Initially, many firms enter in the attempt to exploit the opportunities provided by a new product. Over the product life cycle, increasing economies of scale combined with learning economies in $\mathrm{R} \& \mathrm{D}$, lead to a rapid rise in the minimum efficient scale. The resulting higher entry barriers limit new entry, and price competition forces the less efficient firms to exit. This 'shakeout' phenomenon leads to a rapid fall in the number of participating firms, and the industry becomes highly concentrated (Klepper 1996; Klepper \& Simons 1997). ${ }^{1}$

Since the introduction of the PLC concept, economic geographers have discussed the spatial implications of PLC theory (Thompson 1968; Rees 1979; Markusen 1985; Davelaar 1991; Duranton \& Puga 2001). The main hypothesis in a spatial context holds that industries at an early stage in their lifecycles will be over-represented in the metropolitan core areas, while mature industries are expected to be over-represented in peripheral areas. Metropolitan areas where venture capital, talent, early users and supporting institutions are more abundant are more likely to host (usually) small firms, in emerging industries, which exploit these attributes for their product innovation activities. Larger firms in mature industries are more likely to be located in peripheral areas in order to benefit from low wages, lower 
land prices and less stringent environmental regulations. As an industry moves from the explorative to the mature lifecycle stage, its dominant location can be expected to migrate from the core to the periphery (with the reverse occurring in the case of a dematuring industry). The shift from exploration to standardisation is accompanied with a shift from product to process innovation. This changes the nature of the competition from predominantly product competition to mostly cost competition, which favours firms in low-cost locations. PLC theory predicts that the pattern of relocation will be mainly from the core to the periphery (Duranton \& Puga 2001).

Empirical studies addressing the spatial PLC thesis are based on longitudinal data used to investigate whether the location of industries shifts from core to periphery over time. Both the study by Markusen (1985) and a follow-up study by Sorenson (1997) examine the dispersion patterns for a small number of US manufacturing industries in the periods 1954-1977 and 1954-1987 respectively. Both studies show that the pattern of increasing spatial dispersion predicted by PLC theory is confirmed only for a small number of industries. In a more recent study on France, Pumain et al. (2006) find that in the period 1960-2000 the electronics, chemicals, textiles, metal products, machinery and equipment, and wood, pulp and paper industries progressively relocated from metropolitan to smaller cities. At the same time, in the period considered, the metropolitan cities became increasingly specialised in $\mathrm{R} \& \mathrm{D}$. Contrary to the aforementioned US studies, the French evidence regarding the location pattern of industries over the product lifecycle is more robust.

Spatial PLC theory predicts that the dominant firm migration flow involves firms relocating from a diversified core to a specialist location in the periphery after achieving mass-production of a standardised product. These predicted relocation patterns are indeed observed in many studies in different ways. Duranton and Puga (2001), for example, find that most relocating French firms move from more diverse areas (typically the large metropolitan areas) to less diverse areas in the corresponding sector (typically the smaller cities). They also observe that hightech industries account for a much higher share of relocations than mature sectors (which are already over-represented in the periphery). In a study of Portuguese firms, Holl (2004) finds that start-ups are attracted by large diversified cities while relocating firms are attracted to locations with a specialised industrial base and good road infrastructure. Pellenbarg and Van Steen (2003) find that most inter-regional relocations in the Netherlands involve firms leaving the metropolitan core. This finding resonates with more recent findings by Weterings and Knoben (2013) who found that Dutch firms in innovative and urban areas are more likely to relocate over long-distance. And, distinguishing between manufacturing and services firms, Kronenberg (2013) found that the more densely populated a region is, the more likely manufacturing firms (low and medium-tech) leave, and the less likely knowledge-intensive service firms leave.

If we translate the PLC theory to the present-day economy, most of the new product lifecycles start in the ICT-sector or in ICT-related sectors, which are all part of the current dominant techno-economic paradigm (Perez 2010). Hence, the ICT-related sectors are expected to be over-represented in the core area. By contrast, mature sectors associated with the past techno-economic paradigm, otherwise indicated as the Fordist paradigm (Castellacci 2008), are expected to be over-represented in the periphery as Fordist sectors tend to be oriented towards largescale production and physical distribution. Regarding the industrial dynamics, however, both type of sectors should display the expected pattern of declining entry and exit rates and increasing size and growth rates, when moving from the core, via the semiperiphery, to the periphery. Independent of whether one defines a sector as ICT-related or Fordist, new product cycles start in sectors of both types, and, hence, the industrial dynamics associated with product cycles follows the same spatial product lifecycle logic.

Next to the distinction between ICT versus Fordist sectors, the distinction between manufacturing and service sectors is highly 
relevant. Since spatial PLC theory was originally conceived as a model to explain the location patterns of manufacturing industries, a theoretical question that remains is whether the spatial product lifecycle also applies the service industries (Barras 1986; Gallouj 1998). It can be argued that the innovation and location logics over the course of the lifecycle of a service are different from manufacturing product. As for manufacturing, one can expect core areas to be equally well-suited to generate new services. Once a service has become standardised and is being massproduced, the routinised operations can be located in peripheral areas with lower factor prices, either by fully relocating the firm, or by splitting key front-office activities from routinised back office operations, or by outsourcing back office operations to specialised service providers.

Although the economic logic of moving routinised activities to areas with lower ages equally applies to manufacturing and services, it is expected to be less pervasive in services than in manufacturing, since many services, even if routinised, continue to depend on close physical proximity to users for their effective provision. Indeed, relatively few services can be delivered at a distance by phone or Internet. This means that the spatial differentiation between new and mature service industries may not be as pronounced as between new and mature manufacturing products. It also implies that the industrial dynamics in service industries - in terms of entry, exit, size and growth - may be largely similar in core and peripheral areas.

Indeed, given that the provision of services generally requires consumers and producers to be co-located, the spatial distribution of service industries tend to follow the distribution of population more generally, with the exception of knowledge-intensive business services (KIBS) which are over-represented in larger cities (Pumain et al. 2006). The tendency for KIBS to locate in core urban areas has been mainly attributed to forces of globalisation (Sassen 2001). However, it also reflects the localised complementarities between business services and innovative industries, including the ICT-industry (Meliciani \& Savona 2015). Indeed, innovations in all sectors is supported by specialised KIBS active in R\&D, legal and financial services, and marketing. Hence, following product lifecycle theory, one expects that KIBS, as part of the ICT paradigm, to be over-represented in the metropolitan core of a country and under-represented in its periphery.

\section{METHODOLOGY}

The approach in this paper is to analyse sectors by pooling observations from several years and comparing industrial dynamics across the core, semi-periphery and periphery. We use data on location, entry, exit, size, growth and location of all Dutch firms, thereby including all firm sizes and all sectors, including the service sectors. Our observation period covers the years 1994 to 2005.

To compare the location patterns of sectors in the context of PLC theory, we need to classify sectors into PLC stages. In the absence of comprehensive innovation data for all sectors (let alone firms), we use Pavitt's (1984) taxonomy. Based on a detailed analysis of about 2,000 UK inventions and respective firms in 1945 to 1979 , Pavitt (1984) proposed a four sector taxonomy based on size, innovation patterns and sources of innovation: scale-intensive, supplier-dominated, science-based and specialised supplier.

Miozzo and Soete (2001) proposed to take out services from the supplier-dominated category in Pavitt's original classification, and suggested four additional categories: supplier-dominated services, physical network services, information network services and knowledge-intensive business services. This led to an eight-fold taxonomy to which we refer to as the Pavitt-Miozzo-Soete taxonomy, including four manufacturing and four service sectors. In a further analysis and validation study by Castellacci (2008), it was pointed out that, as for the four manufacturing sectors, the new taxonomy of four service sectors is indeed empirically meaningful, if one looks at differences in size, innovation patterns and sources of innovation (with special attention to the role of ICT). As such, the Pavitt-Miozzo-Soete taxonomy can be 
considered a validate taxonomy, and became used in other studies (e.g. Castaldi 2009).

The Pavitt-Miozzo-Soete taxonomy can be summarised below (Castellacci 2008; Castaldi 2009). First with manufacturing:

- scale-intensive (SI): includes both complex and consumer durables (food, chemicals, motor vehicles), and processed raw materials (e.g. metal manufacturing, glass and cement). Firms tend to be large and to rely mainly on internal resources for their innovations. Carrier industries in the Fordist paradigm;

- supplier-dominated (SD): includes industries where firms mostly produce technologically simple goods (e.g. textiles, leather goods, pulp and paper), where the capital and intermediate components suppliers are the main sources of innovation;

- science-based (SB): includes industries where innovation is linked directly to advances in academic research (e.g. pharmaceuticals, electronics, scientific instruments). Innovation rates are particularly high. Carrier industries in the ICT paradigm; and

- specialised supplier (SS): includes equipment building, design and mechanical engineering, where innovation typically emerges from informal activities. Firms in this group tend to be small, and innovation rates particularly high. Supportive of the Fordist paradigm.

Second with services:

- supplier-dominated services (SDS): rely on the purchase of capital goods for their innovation. They are mostly small companies providing services directly to customers (e.g. hotels, restaurants, rental services and personal services). Innovation rates are particularly low;

- physical network services (PNS): include all transport, retail and wholesale trade related services. Supportive of the Fordist paradigm;

- information network services (INS): include all information-intensive activities (communication, financial intermediation, insurance, real estate). Firms tend to be large and to innovate in interaction with suppliers and users. Supportive of the ICT paradigm; and
- knowledge intensive business services (KIBS): include R\&D services, consultancy and computer-related activities. Firms tend to be small and medium firms that produce their own innovation. Innovation rates are particularly high. Supportive of the ICT paradigm.

Our study compares the industrial dynamics in the core, semi-periphery and periphery for the economy as a whole, and for each PavittMiozzo-Soete sector separately. We first check the basic prediction of PLC theory regarding the location patterns of different sectors. Sectors based on the Fordist paradigm (SI, SS, PNS) are expected to be over-represented in the periphery, while the sectors based on the ICT-paradigm (SB, INS, KIBS) should be over-represented in the core. In order to analyse location patterns we calculate the natural logarithm of the ratio of the area's sectoral level employment shares and the area's total employment share:

$$
\operatorname{loc}_{g i}=\ln \left(\frac{E m p l_{g i} / \sum_{a} E m p l_{a i}}{\sum_{j} E m p l_{g j} / \sum_{a} \sum_{j} E m p l_{a j}}\right)
$$

where $g, a=$ core, semi-periphery, periphery ( $a$ being a generic geographical area and $g$ the geographical area under study), and $i$, $j=1, \ldots, 8$ represent Pavitt's four manufacturing sectors and Miozzo-Soete's four service sectors ( $j$ being a generic sector and $i$ the sector under study). We choose the logtransformation of this ratio as to render the values symmetric around zero. Negative values denote under-representation in a particular area, and positive values denote overrepresentation in a particular area. ${ }^{2}$

We then look at spatial differentiation in entry, exit, size, and persistent growth. Following spatial PLC theory, we expect the core to show the highest entry and exit rates and the highest share of what we call 'microfirms', defined as firms with less than four employees. These numbers should decrease when moving from the core to the semiperiphery and then to the periphery. For each geographical area $g$ and each sector $i$, we compute a weighted average of the yearly entry rates between 1995 and 2005, where 
the weights correspond to the yearly total number of existing firms (total) in each year $t$ between 1995 and 2005, as in the following:

$$
\begin{aligned}
\text { entry_rate }_{\text {gi }} & =\frac{\sum_{t=1995}^{2005} \text { entries }_{\text {git }}}{\sum_{t=1995}^{2005} \text { total }_{\text {git }}} \\
& =\frac{\sum_{t=1995}^{2005}\left(\frac{\text { entries }_{\text {git }}}{\text { totalg }_{\text {git }}} \times \text { total }_{\text {git }}\right)}{\sum_{t=1995}^{2005} \text { total }_{\text {git }}} \\
& =\frac{\sum_{t=1995}^{2005}\left(\text { entry_rate }_{\text {git }} \times \text { total }_{\text {git }}\right)}{\sum_{t=1995}^{2005} \text { total }_{\text {git }}}
\end{aligned}
$$

where: $g=$ core, semi-periphery, periphery; and $i=1, \ldots, 8$ represents the four manufacturing sectors and the four service sectors respectively according to the Pavitt-MiozzoSoete taxonomy. From hereon, we consider this weighted average whenever we refer to the entry rate of a given area without specifying a particular year.

We use an analogous method to build a weighted average of the exit rates:

$$
\begin{aligned}
\text { exit_rate }_{\text {gi }} & =\frac{\sum_{t=1995}^{2005} \text { exits }_{\text {git }}}{\sum_{t=1995}^{2005} \text { total }_{\text {git }-1}} \\
& =\frac{\sum_{t=1995}^{2005}\left(\frac{\text { exits }_{\text {git }}}{\text { total }_{\text {git }-1}} \times \text { total }_{\text {git }-1}\right)}{\sum_{t=1995}^{2005} \text { total }_{\text {git }-1}} \\
& =\frac{\sum_{t=1995}^{2005}\left(\text { exit_rate }_{\text {git }} \times \text { total }_{\text {git }-1}\right)}{\sum_{t=1995}^{2005} \text { total }_{\text {git }-1}}
\end{aligned}
$$

Differences in firm size distributions across core, semi-periphery and periphery are taken into account by looking at average size as well as the share of firms with less than four employees and the share of firms with more than 100 employees. Following the spatial product lifecycle, we expect firms in the core on average to be smaller and firms in the periphery to be larger.

We also look at firm growth patterns (in terms of numbers of employees). Here, spatial PLC teaches us that, given the high wages and high land prices in the core compared to the periphery, we should expect to find fewer growing firms in the core than in the periphery. We look at persistently growing firms, that is, firms that experience positive growth in two consecutive years (cf. Capasso et al. 2014), and we show the share of persistently growing firms in different spatial areas and in different sectors. For each year $t$, we balance the panel with years $t+1$ and $t+2$, that is we consider only the firms that are surviving over the three-year time span, and we call 'persistent growers' the firms that have experienced a positive growth rate both between $t$ and $t+1$, and between $t+1$ and $t+2$. After summing the number of persistent growers for all the years of our dataset, we divide the sum by the total number of firms considered in the analysis, that is by the sum of the numbers of firms that are operational in each whole three-year interval.

\section{DATA}

Our data are provided by Statistics Netherlands (CBS) from the Business Register (BR) of enterprises. The BR database includes the entire population of firms registered for fiscal purposes in the Netherlands, in the year considered. The database contains detailed information on sector at the 5-digit SBI (the Dutch Standard Industry Classification (SIC) ) level, number of employees and dates of market entry and exit. Relocating firms are treated as new entries if their move is combined with a large increase/decrease in employment. Given that precise identification of relocating firms is not possible, our analysis considers only firms that survived and remained in the same area (core, semiperiphery or periphery) for the whole of the time span considered (2 years or 3 years, depending on the statistics computed). Our observation period covers the years 1994 to 2005. The population includes selfemployment (firms with zero employees), which we refer to as size one firms.

For firms with multiple sites, total employment is based on the location acting as the firm's address for fiscal purposes, which is a limitation because firms with multiple establishments may be active in multiple sectors, while in our data all firms 
are by definition part of a single sector only. (Note that since the fiscal address is generally the headquarter address, and assuming headquarters are over-represented in the core region, we most probably have a slightly higher estimate of firm size in the core and a slightly lower estimate of firm size in the periphery. Given that our hypothesis following the spatial product life cycle thesis holds that firms should be smaller in size in the core than in the periphery, this treatment of multi-site firms renders our conclusion conservative.)

The Pavitt-Miozzo-Soete taxonomy used for this study corresponds to the classification in Castaldi (2009) with the exception of SIC classes 334 and 335 (optical and other instruments), which we reclassified as SS (see e.g. Bürger \& Cantner 2010). The list of SIC sectors and the corresponding Pavitt-Miozzo-Soete sector is provided in Table 1.

The classification of Dutch regions into core, semi-periphery and periphery is taken from Van Oort (2004). On the map of The Netherlands in Figure 1, the 40 labour market regions (NUTS 3) are depicted as well as their aggregation into Van Oort's classification of NUTS 3 regions into the three macro-areas, indicated by core, semiperiphery and periphery. This classification of labour market regions is based on an economic potential function that measures the density of jobs (Van Oort 2004). The single core area coincides with the so-called Randstad-area comprising of the four largest cities in the country as well as their suburbs and some other smaller towns. The semiperiphery borders the core area and has a lower density of jobs than the core area, but a higher density than the periphery. As a robustness check, we validated Van Oort's classification by testing whether relative wage levels significantly decline when moving from core, to semi-periphery to periphery, which was found to be the case (see Table 2). Given that the spatial PLC reasons from firms looking for lower wages as their product matures, we conclude that Van Oort's classification of regions into core, semi-periphery and periphery is meaningful in the context of our empirical study:
- the densely populated core metropolitan area in the western part of the Netherlands which includes the four largest cities of Amsterdam, Rotterdam, The Hague and Utrecht, and the Port of Rotterdam and Amsterdam's Schiphol Airport, accounting for 48 per cent of employment in the eight sectors. Ten NUTS 3 regions are included in the core;

- the less densely populated semi-periphery covering the regions adjacent to the core area (with Eindhoven, Tilburg and Nijmegen as the main cities), providing 29 per cent of employment in the eight sectors. Eleven NUTS 3 regions are included in the semi-periphery; and

- the least populated periphery at the Northern, Eastern and Southern borders (with Groningen in the north, Enschede in the east, and Maastricht in the south as the main cities) providing 23 per cent of employment in the eight sectors. Nineteen NUTS 3 regions are included in the periphery.

\section{RESULTS}

Location patterns - We start by analysing the location pattern of different sectors using equation (1), that is dividing the employment share of an area in a sector by the employment share of the area in all sectors, and taking the logarithm of the result. Negative values indicate under-representation in a particular area and positive values indicate over-representation in a particular area. The hypothesis holds that the carrier and supporting sectors in the ICT paradigm (SB, INS, KIBS) are over-represented in the core, and the carrier and supporting sectors in the Fordist paradigm (SI, SS, PNS) are overrepresented in the periphery.

Results are given in Table 3 . If we turn to the ICT paradigm sectors, we observe that INS and KIBS follow the predicted pattern of over-representation in the core, while SB is over-represented in the semi-periphery. Thus, while SB does not exactly follow the predictions within the ICT paradigm, the other sectors belonging to the ICT paradigm are highly over-represented in the core. Turning 
Table 1. SIC codes and corresponding Pavitt-Miozzo-Soete, sectors.

\begin{tabular}{|c|c|c|}
\hline Industries & SIC & PMS \\
\hline Food, drink and tobacco & $15-16$ & SI \\
\hline Textiles and clothing & $17-18$ & SD \\
\hline Leather and footwear & 19 & SD \\
\hline Wood and products of wood and cork & 20 & $\mathrm{SD}$ \\
\hline Pulp, paper and paper products & 21 & SD \\
\hline Printing and publishing & 22 & SD \\
\hline Mineral oil refining, coke and nuclear fuel & 23 & SI \\
\hline Pharmaceuticals & 244 & SB \\
\hline Chemicals excl. Pharmaceuticals & $24 \times$ & SI \\
\hline Rubber and plastics & 25 & SI \\
\hline Non-metallic mineral products & 26 & SI \\
\hline Basic metals & 27 & SI \\
\hline Fabricated metal products & 28 & SI \\
\hline Mechanical engineering & 29 & SS \\
\hline Office machinery & 30 & SB \\
\hline Insulated wire & 313 & SD \\
\hline Other electrical machinery and apparatus & $31 \times$ & SS \\
\hline Radio, TV and comm. Equipment & 32 & SB \\
\hline Scientific instruments & $331-3$ & SB \\
\hline Optical and other instruments & $334-5$ & SS \\
\hline Motor vehicles & 34 & SI \\
\hline Other transport equipment & 35 & SI \\
\hline Furniture, miscellaneous manufacturing; recycling & $36-37$ & SD \\
\hline Sale, maintenance and repair of motor vehicles; retail sale of automotive fuel & 50 & PNS \\
\hline Wholesale trade and commission trade, exc. motor vehicles & 51 & PNS \\
\hline Retail trade, exc. motor vehicles; repair of personal and household goods & 52 & PNS \\
\hline Hotels and restaurants & 55 & SDS \\
\hline Inland transport & 60 & PNS \\
\hline Water transport & 61 & PNS \\
\hline Air transport & 62 & PNS \\
\hline Supporting and aux. transport activities; activities of travel agencies & 63 & PNS \\
\hline Communications & 64 & INS \\
\hline Financial intermediation & $65-67$ & INS \\
\hline Real estate activities & 70 & INS \\
\hline Renting of machinery and equipment & 71 & SDS \\
\hline Computer and related activities & 72 & KIBS \\
\hline Research and development & 73 & KIBS \\
\hline Other business activities & 74 & KIBS \\
\hline Other community, social and personal services & $90-93$ & SDS \\
\hline
\end{tabular}

to the Fordist paradigm sectors, we observe the predicted pattern for SI and SD of overrepresentation in the periphery, while the values for PNS are very close to zero indicating that this sector follows the economy-wide location patterns. ${ }^{3}$ Thus, consistent with spatial PLC theory, the location patterns of the sectors operating primarily in the Fordist paradigm are almost the reverse of the location patterns for the sectors in the ICT paradigm.
Note here that the strong presence of science-based manufacturing in the semiperiphery may reflect that the core does not provide the ideal context for high-tech firms. Rather, since the core is dominated by (ICTbased) service sectors, science-based manufacturing is crowded out to the surrounding semi-periphery. This may well indicate that science-based firms in the semi-periphery can profit from the services provided by the 


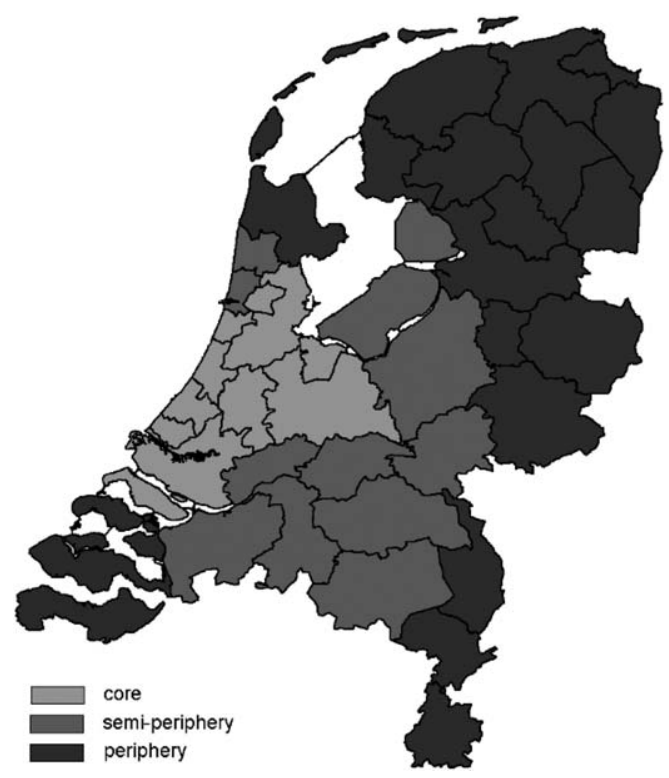

nearby core without having to bear the diseconomies associated with agglomeration. This pattern may apply also to other countries where large metropolises have become functionally specialised in ICT-based business services possibly generating negative externalities for science-based manufacturing, with the latter pushed to the surrounding areas (Duranton \& Puga 2005) and, often, with universities active in technology transfer (Etzkowitz \& Leydesdorff 2000).

Industrial dynamics - Table 4 provides the results for entry rate as in (2), exit rate as in (3) average size, share of firms having at most 3 employees, share of firms having more than 100 employees, and share of persistent growers, for firms in all eight sectors for respectively the core, semi-peripheral and peripheral areas, and for the country as a

Figure 1. Map of The Netherlands.

Table 2. Wage level differences.

\begin{tabular}{lclll}
\hline Wages mean (log) & Welch's t-test & & & \\
\hline core & 0.1733 & core-periphery difference & $0.9303 * * *$ & $(0.1056)$ \\
semiperiphery & -0.2881 & core-semiperiphery difference & $0.4615 * * *$ & $(0.1079)$ \\
periphery & -0.7570 & semiperiphery-periphery differ. & $0.4688^{*} * *$ & $(0.0793)$ \\
whole country & -0.3955 & & &
\end{tabular}

Notes: $* 10 \%$ significance; $* * 5 \%$ significance; $* * * 1 \%$ significance. Left column: log relative wage (computed at NUTS 3 level), averaged across respectively core regions, semi-periphery regions, and periphery regions. Right column: Welch's t-test (statistics and standard errors), of the pair-wise differences of the average wage among core regions, semi-periphery regions, and periphery regions.

Table 3. Sectoral location patterns.

\begin{tabular}{|c|c|c|c|c|}
\hline & & Core & Semi-periphery & Periphery \\
\hline \multicolumn{5}{|l|}{ Manufacturing } \\
\hline Scale-intensive (SI) & Fordist & -0.525 & 0.273 & 0.375 \\
\hline Supplier-dominated (SD) & & -0.452 & 0.145 & 0.443 \\
\hline Science-based (SB) & ICT & -0.844 & 0.677 & -0.022 \\
\hline Specialised supplier (SS) & Fordist & -0.552 & 0.295 & 0.371 \\
\hline \multicolumn{5}{|l|}{ Services } \\
\hline Supplier-dominated services (SDS) & & -0.041 & -0.057 & 0.141 \\
\hline Physical network services (PNS) & Fordist & -0.034 & 0.044 & 0.014 \\
\hline Information network services (INS) & ICT & 0.389 & -0.558 & -0.600 \\
\hline KIBS & ICT & 0.192 & -0.123 & -0.347 \\
\hline
\end{tabular}

Notes: Natural logarithm of the ratio between area's employment shares at sectoral level and area's total employment share. Negative values indicate under-representation in a particular area and positive values over-representation in a particular area. 
Table 4. Descriptive statistics (all sectors).

\begin{tabular}{|c|c|c|c|c|}
\hline All sectors & Core & Semi-periphery & Periphery & Whole country \\
\hline Entry rate & 0.1263 & 0.1167 & 0.1095 & 0.1188 \\
\hline Exit rate & 0.1092 & 0.0962 & 0.0912 & 0.1004 \\
\hline Average size & 7.8367 & 6.4873 & 5.9618 & 6.9184 \\
\hline Size $=1,2,3$ & 0.7703 & 0.7486 & 0.7372 & 0.7547 \\
\hline Size $>100$ & 0.0065 & 0.0059 & 0.0054 & 0.0060 \\
\hline Total number of firms & $3,976,851$ & $2,879,578$ & $2,520,304$ & $9,376,733$ \\
\hline Persistent growers & 0.0115 & 0.0126 & 0.0121 & 0.0120 \\
\hline
\end{tabular}

whole. These results are based on pooling all observations in the period 1994-2005 (i.e. using an unbalanced panel).
If we first look at the level of the whole economy, we can confirm the standard PLC hypothesis that entry and exit rates are

Table 5. Descriptive statistics per sector: manufacturing.

\begin{tabular}{|c|c|c|c|c|}
\hline & Core & Semi-periphery & Periphery & Whole country \\
\hline \multicolumn{5}{|l|}{ Scale-intensive (SI) } \\
\hline Entry rate & 0.0863 & 0.0822 & 0.0761 & 0.0813 \\
\hline Exit rate & 0.0850 & 0.0725 & 0.0708 & 0.0756 \\
\hline Average size & 20.1697 & 21.7622 & 20.5620 & 20.8822 \\
\hline Size $=1,2,3$ & 0.5164 & 0.4766 & 0.4733 & 0.4872 \\
\hline Size $>100$ & 0.0320 & 0.0349 & 0.0378 & 0.0351 \\
\hline Total number of firms & 85,410 & 105,311 & 99,333 & 290,054 \\
\hline Share of persistent growers & 0.0208 & 0.0306 & 0.0315 & 0.0281 \\
\hline \multicolumn{5}{|l|}{ Supplier-dominated (SD) } \\
\hline Entry rate & 0.1002 & 0.0882 & 0.0867 & 0.0922 \\
\hline Exit rate & 0.0914 & 0.0796 & 0.0747 & 0.0826 \\
\hline Average size & 10.3526 & 12.2977 & 15.9161 & 12.6105 \\
\hline Size $=1,2,3$ & 0.7138 & 0.6651 & 0.6618 & 0.6823 \\
\hline Size $>100$ & 0.0121 & 0.0136 & 0.0224 & 0.0155 \\
\hline Total number of firms & 125,097 & 114,606 & 96,294 & 335,997 \\
\hline Share of persistent growers & 0.0128 & 0.0156 & 0.0182 & 0.0153 \\
\hline \multicolumn{5}{|l|}{ Science-based (SB) } \\
\hline Entry rate & 0.0885 & 0.1022 & 0.0933 & 0.0945 \\
\hline Exit rate & 0.0713 & 0.0727 & 0.0651 & 0.0700 \\
\hline Average size & 13.5214 & 41.6817 & 20.2692 & 24.9574 \\
\hline Size $=1,2,3$ & 0.6705 & 0.6212 & 0.6084 & 0.6364 \\
\hline Size $>100$ & 0.0224 & 0.0213 & 0.0262 & 0.0231 \\
\hline Total number of firms & 16,539 & 14,716 & 12,153 & 43,408 \\
\hline Share of persistent growers & 0.0173 & 0.0275 & 0.0257 & 0.0231 \\
\hline \multicolumn{5}{|l|}{ Specialised supplier (SS) } \\
\hline Entry rate & 0.0884 & 0.0940 & 0.0855 & 0.0896 \\
\hline Exit rate & 0.0754 & 0.0681 & 0.0662 & 0.0696 \\
\hline Average size & 17.1356 & 18.5239 & 18.3281 & 18.0533 \\
\hline Size $=1,2,3$ & 0.5287 & 0.5115 & 0.4741 & 0.5042 \\
\hline Size $>100$ & 0.0324 & 0.0337 & 0.0368 & 0.0343 \\
\hline Total number of firms & 23,120 & 29,908 & 25,983 & 79,011 \\
\hline Share of persistent growers & 0.0255 & 0.0347 & 0.0359 & 0.0324 \\
\hline
\end{tabular}


highest in the core and lowest in the periphery, with the semi-periphery taking intermediate values. Hence, the basic prediction of the spatial PLC holds - that PLCs tend to start in the core leading to higher entry and exit rates in the core compared to the periphery.

In terms of size differences, we observe that - unexpectedly - firms in the core are on average larger than firms in the periphery, with the semi-periphery again taking an intermediate value. Based on spatial PLC theory, we expected that firms in the core would be of smaller average size than those in the periphery. However, this finding should be interpreted with caution since the underlying firm size distributions are extremely skewed.
To get a better sense of the spatial size differentiation, it is helpful to look at the share of firms with at most three employees. This indicator is more revealing since this is the most frequent firm size class. This indicator shows the expected patterns with the core having the largest share of these micro-firms, followed by the semi-periphery and the periphery. Thus, although average size is larger in the core than the periphery and semiperiphery, the core also hosts the largest share of micro-firms, indicating that the variance of the $\log$ size distribution is likely to be higher in the core area. Notice that not only micro firms, but also large firms are more likely to be located in the core area, as

Table 6. Descriptive statistics per sector: services.

\begin{tabular}{|c|c|c|c|c|}
\hline & Core & Semi-periphery & Periphery & Whole country \\
\hline \multicolumn{5}{|c|}{ Supplier-dominated services (SDS) } \\
\hline Entry rate & 0.1118 & 0.1074 & 0.1018 & 0.1074 \\
\hline Exit rate & 0.0821 & 0.0754 & 0.0761 & 0.0782 \\
\hline Average size & 5.5028 & 4.3688 & 3.9517 & 4.6824 \\
\hline Size $=1,2,3$ & 0.7479 & 0.7524 & 0.7483 & 0.7493 \\
\hline Size $>100$ & 0.0048 & 0.0026 & 0.0016 & 0.0031 \\
\hline Total number of firms & 730,365 & 542,541 & 587,204 & $1,860,110$ \\
\hline Share of persistent growers & 0.0099 & 0.0084 & 0.0076 & 0.0087 \\
\hline \multicolumn{5}{|l|}{ Physical network services (PNS) } \\
\hline Entry rate & 0.1111 & 0.1008 & 0.0959 & 0.1035 \\
\hline Exit rate & 0.1026 & 0.0871 & 0.0830 & 0.0922 \\
\hline Average size & 7.7352 & 6.3200 & 5.4511 & 6.6355 \\
\hline Size $=1,2,3$ & 0.7128 & 0.6933 & 0.6867 & 0.6992 \\
\hline Size $>100$ & 0.0060 & 0.0049 & 0.0033 & 0.0049 \\
\hline Total number of firms & $1,312,718$ & $1,040,821$ & 941,575 & $3,295,114$ \\
\hline Share of persistent growers & 0.0133 & 0.0144 & 0.0133 & 0.0137 \\
\hline \multicolumn{5}{|c|}{ Information network services (INS) } \\
\hline Entry rate & 0.1488 & 0.1441 & 0.1356 & 0.1445 \\
\hline Exit rate & 0.1842 & 0.1720 & 0.1597 & 0.1752 \\
\hline Average size & 8.7514 & 3.4414 & 3.4258 & 6.0273 \\
\hline Size $=1,2,3$ & 0.8724 & 0.8653 & 0.8560 & 0.8667 \\
\hline Size $>100$ & 0.0041 & 0.0019 & 0.0017 & 0.0029 \\
\hline Total number of firms & 546,739 & 323,652 & 250,776 & $1,121,167$ \\
\hline Share of persistent growers & 0.0074 & 0.0074 & 0.0078 & 0.0075 \\
\hline \multicolumn{5}{|l|}{ KIBS } \\
\hline Entry rate & 0.1498 & 0.1457 & 0.1432 & 0.1471 \\
\hline Exit rate & 0.1029 & 0.0987 & 0.0992 & 0.1008 \\
\hline Average size & 7.5383 & 5.2965 & 4.7648 & 6.2655 \\
\hline Size $=1,2,3$ & 0.8336 & 0.8404 & 0.8418 & 0.8374 \\
\hline Size $>100$ & 0.0061 & 0.0047 & 0.0041 & 0.0052 \\
\hline Total number of firms & $1,136,863$ & 708,023 & 506,986 & $2,351,872$ \\
\hline Share of persistent growers & 0.0104 & 0.0101 & 0.0099 & 0.0102 \\
\hline
\end{tabular}


witnessed by the higher proportion of firms having more than 100 employees in the core.

We also observe that (unexpectedly) the semi-periphery has the highest share of persistently growing firms. This result is based on firms that had grown two years in a row. We obtain the same result if we redefine persistent growth as a sequence of three rather than two consecutive growth events. This pattern contradicts the spatial PLC that would predict the share of persistently growing firms to be highest in the periphery.

The PLC predictions for the industrial dynamics at the level of the whole economy, should also apply at the level of the eight sectors we distinguished, since each sector will experience new product cycles generating the expected industrial dynamics in the respective sector. In Tables 5 and 6 we present the results of the same statistics as Table 4, but now computed separately for the eight sectors (Table 5 for manufacturing and Table 6 for services). Indeed, as for the whole economy, entry and exit rates are highest in the core and lowest in the periphery for all sectors, with the exception of $\mathrm{SB}$, where the highest entry and exit rates are observed in the semi-periphery, and of SS, where the highest entry rate is observed in the semi-periphery.

Looking at the share of firms with at most three employees, we see that, with the exception of SDS and KIBS, all sectors follow the predicted core-periphery pattern. The sectoral disaggregation also allows to observe whether large firms having more than 100 employees are more likely to be located in the periphery as the PLC theory predicts. This is only in the case for sectors belonging to manufacturing while in all four service sectors large firms more often locate in the core. This important finding suggests that all service sectors are (still) sensitive to proximity to consumer markets, with the larger size of firms in core areas reflecting the denser consumer markets in these areas. That is, there is little evidence that vertical disintegration and relocation to peripheral regions is a pervasive phenomenon. Along the same lines, the prediction that persistently growing firms occur more often in the periphery than in the core only holds for manufacturing, while no such evidence is found for service sectors.

\section{CONCLUDING REMARKS}

Our study presented systematic findings on the sectoral specialisation patterns and industrial dynamics in core, semi-peripheral and peripheral areas in the Netherlands. We believe that a thorough understanding of the spatial differentiation of industrial dynamics is important to understand the different paths of development across regions and, ultimately, to design specific urban and regional policies to influence these paths. For example, entrepreneurship policies may work well only in sectoral and regional contexts where innovation is, indeed, driven by entrepreneurship. Reversely, in context where large productionoriented firms dominate, supply-chain policies may be more effective. Though our study is informative regarding policy design, the further elaboration of regional policy implications is beyond the scope of the paper.

Empirically, we can draw two main conclusions from our empirical analysis of location patterns and industrial dynamics in the core, semi-periphery and periphery. First, we analysed the location patterns of different sectors by distinguishing between sectors central to ICT paradigm with many products and services at an early stage in their lifecycle, and sectors belonging to the Fordist paradigm with many products and services at a mature stage in their lifecycle. As expected, sectors operating primarily in the ICT paradigm were found to be over-represented in the core - with the exception of sciencebased industries that are concentrated in the semi-periphery - while the opposite location pattern holds for sectors in the Fordist paradigm, which are over-represented in the periphery. Thus, the location patterns of all sectors are in line with the predictions of the spatial PLC theory, though the location of science-based firms present an anomaly. Possibly, with the core being dominated by (ICT-based) service sectors, science-based manufacturing is crowded out to the surrounding semi-periphery.

Second, at the level of the whole economy, the spatial differentiation of industrial dynamics is also largely consistent with spatial product life cycle thesis: entry and exit rates are highest in the core and lowest in the 
periphery, while the share of persistently growing firms is higher in the periphery than in the core. However, when differentiating between manufacturing and services, we observe that manufacturing sectors mostly follow the patterns predicted by the product life cycle theory, while service sectors sometimes contradict product life cycle theory. In particular, large service firms and persistently growing service firms occur more often in the core rather than in the periphery, which present us with a second anomaly given the theory. We understand this finding as reflecting that service sectors remain sensitive to proximity to consumer markets, and that larger size of firms in core areas reflect the denser consumer markets in core areas.

Overall, we conclude that the spatial product lifecycle theory applies well to traditional manufacturing, while more specific theories are required to understand the location and industrial dynamics of science-based industries and service industries. Particularly, current theories that build on the product life cycle as a core model, both in the neoclassical tradition (Duranton \& Puga 2001) and the evolutionary tradition (Boschma \& Frenken 2006), should recognise that their models apply primarily to manufacturing products. In both cases, more specific models regarding the lifecycle of science-based and service industries, and their spatial implications, remain to be developed.

The future challenge is to extend our theoretical models and empirical studies to capture the specific spatial characteristics of industrial dynamics in modern science-based and service industries, in line with earlier observations (Consoli 2005; Duranton \& Puga 2005; Heebels \& Boschma 2011; De Beule \& Van Beveren 2012). Our study provides a first systematic attempt in this direction by theorising and analysing firm size, industrial dynamics and location patterns of firms across all sectors in the economy. Nevertheless, our study remained limited to a single country. More evidence for other countries is needed to come to more nuanced stylised facts about the spatial product lifecycle dynamics. Most probably, more elaborated theories will then be required to explain such facts in full detail.

\section{Acknowledgements}

This work was supported by Utrecht University [High Potential Grant (HIPO) to E. Cefis and K. Frenken]; and the University of Bergamo [grant ex $60 \%$, n. 60CEFI13, Department of Management, Economics and Quantitative Methods, to E. Cefis]. The empirical analysis for this research was carried out at the Centre for Research of Economic Microdata at Statistics Netherlands (CBS). The views expressed in this paper are those of the authors and do not necessarily reflect the policies of Statistics Netherlands. The authors thank Gerhard Meinen, Ruurd Schoonhoven and CBS on-site staff for their collaboration.

\section{Notes}

1. Various attempts have been made to systematically test the product lifecycle model based on analysis of the data on innovation and industrial dynamics notably by Abernathy and Utterback (1978), Gort and Klepper (1982), Utterback and Suarez (1993), Klepper and Simons (1997) and Malerba and Orsenigo (1996). See for a recent review, Peltoniemi (2011).

2. Various other candidate measures can be considered (on this, see Combes et al. 2008). A discussion of these measures is beyond the scope of this paper. Furthermore, we did not check for alternative zoning definitions otherwise known as the modifiable areal unit problem (Gehlke and Biehl 1934; Briant et al. 2010; Burger et al. 2010). Suffice to say that, since we only deal with three macro-areas, alternative indicators or area definitions are most likely to show the same overall pattern of over and under-representation.

3. We understand this result as reflecting that the location of transportation firms closely follows the location of their clients.

\section{REFERENGES}

Abernathy, W.J. \& J. UtTerback (1978), Patterns of Industrial Innovation. Technology Review 50, pp. $41-47$.

BARRAS, R. (1986), Towards a Theory of Innovation in Services. Research Policy 15, pp. 161-173.

Boschma, R.A. \& K. Frenken (2006), Why is Economic Geography Not an Evolutionary Science? Towards an Evolutionary Economic 
Geography, Journal of Economic Geography 6, pp. 273-302.

Bottazzi, G., E. Cefis, G. Dosi \& A. Secchi (2007), Invariances and Diversities in the Evolution of Manufacturing Industries, Small Business Economics 29, pp. 137-159.

Briant, A, P.-P. COMbeS \& M. LAFOURCADE (2010), Dots to Boxes: Do the Size and Shape of Spatial Units Jeopardize Economic Geography Estimations? Journal of Urban Economics 67, pp. 287-302.

BUrger, M.J., F.G. VAN OORT \& G.A. VAN DER KNAAP (2010), A Treatise on the Geographical Scale of Agglomeration Externalities and the Modifiable Areal Unit Problem. Italian Journal of Regional Science 9, pp. 19-40.

Bürger, M. \& U. CANTner (2010), The Regional Dimension of Sectoral Innovativeness: An Empirical Investigation of Two Specialised Supplier and Two Science-based Industries, Papers in Regional Science 90, pp. 373-393.

Capasso, M., E. Cefis \& K. Frenken (2014), On the Existence of Persistently Outperforming Firms. Industrial and Corporate Change 23, pp. 997-1036.

Castaldi, C. (2009), The Relative Weight of Manufacturing and Services in Europe: An Innovation Perspective, Technological Forecasting and Social Change 76, pp. 709-722.

Castellacci, F. (2008), Technological Paradigms, Regimes and Trajectories: Manufacturing and Service Industries in a New Taxonomy of Sectoral Patterns of Innovation. Research Policy 37, pp. 978-994.

Combes, P.-P., T. MAYER \& J.-F. Thisse (2008), Economic Geography. Princeton, NJ: Princeton University Press.

Consoli, D. (2005), The Dynamics of Technological Change in UK Retail Banking Services: An Evolutionary Perspective. Research Policy 34, pp 461-480.

DAVELAAR, E.J. (1991), Incubation and Innovation. A spatial perspective. Aldershot: Ashgate.

De Beule, F. \& I. VAN Beveren (2012), Does Firm Agglomeration Drive Product Innovation and Renewal? An Application for Belgium. Tijdschrift voor Economische en Sociale Geografie 103, pp. 457-472.

Duranton, G. \& D. PugA (2001), Nursery Cities: Urban Diversity, Process Innovation, and the Life Cycle of Products, American Economic Review 91, pp. 1454-1477.
Duranton, G. \& D. PugA (2005), From Sectoral to Functional Urban Specialisation. Journal of Urban Economics 57, pp. 343-370.

Etzkowitz, H. \& L. LeYDESDORFF (2000), The Dynamics of Innovation: From National Systems and 'Mode 2' to a Triple Helix of Universityindustry-government Relations. Research Policy 29, 109-123.

Frenken, K., E. CeFis \& E. StAm (2015), Industrial Dynamics and Cluster: A Survey. Regional Studies $10,10-27$.

GallouJ, F. (1998), Innovating in Reverse: Services and the Reverse Product Cycle. European Journal of Innovation Management 1 , pp.123-138.

GEHLKE, C. \& K. BieHL (1934), Certain Effects on Grouping upon the Size of the Correlation Coefficient in Census Tract Material. Journal of the American Statistical Association 29, pp. 169-170.

GORT, M. \& S. KlePPER (1982), Time-paths in the Diffusion of Product Innovations. Economic Journal, 92, pp. 630-653.

Heebels, B. \& R. Boschma (2011), Performing in Dutch Book Publishing 1880-2008. The Importance of Entrepreneurial Experience and the Amsterdam Cluster. Journal of Economic Geography 11, pp. 1007-1029.

Holl, A. (2004), Start-ups and Relocations: Manufacturing Plant Location in Portugal. Papers in Regional Science 83(4), pp. 649-668.

KLEPPER, S. (1996), Entry, Exit, Growth, and Innovation over the Product Life Cycle. American Economic Review 86, pp. 562-583.

KLEPPER, S. \& K.L. SimONS (1997), Technological Extinctions of Industrial Firms. Industrial and Corporate Change 6, pp. 379-460.

KronenberG, K. (2013), Firm Relocations in the Netherlands: Why Do Firms Move, and Where Do They Go? Papers in Regional Science 92, pp. 691-713.

LEVITT, T. (1965), Exploit the Product Life Cycle. Harvard Business Review 43, pp. 81-94.

Malerba, F. \& L. Orsenigo (1996), Schumpeterian Patterns of Innovation are Technology-specific. Research Policy 25, pp. 451-478.

Markusen, A. (1985), Profit Cycle, Oligopoly and Regional Development. Cambridge, MA: The MIT Press.

MARsili, O. (2001), The Anatomy and Evolution of Industries: Technological Change and Industrial Dynamics. Cheltenham: Edward Elgar. 
Meliciani, V. \& M. SAVOna (2015), The Determinants of Regional Specialisation in Business Services: Agglomeration Economies, Vertical Linkages and Innovation. Journal of Economic Geography, 15, pp. 387-416.

Miozzo, M. \& L. SoETE (2001), Internationalization of Services: A Technological Perspective. Technological Forecasting and Social Change 67, pp. 159-185.

PAVITT, K. (1984), Sectoral Patterns of Technical Change: Towards a Taxonomy and a Theory. Research Policy 13, pp. 343-373.

PellenbarG, P.H. \& P.J.M. VAn Steen (2003), Spatial Perspectives on Firm Dynamics in the Netherlands, Tijdschrift voor Economische en Sociale Geografie 94, pp. 620-630.

Peltoniemi, M. (2011), Reviewing Industry Life-cycle Theory: Avenues for Future Research. International Journal of Management Reviews 13, pp. 349-375.

Perez, C. (2010), Technological Revolutions and Techno-economic Paradigms. Cambridge Journal of Economics 34, pp. 185-202.

Pumain, D., F. Paulus, C. Vacchiani-Marzucco \& J. LOBO (2006), An Evolutionary Theory for Interpreting Urban Scaling Laws. Cybergeo, article no. 343.

REes, J. (1979), Technological Change and Regional Shifts in American Manufacturing. The Professional Geographer 31, pp. 45-54.

Sassen, S. (2001), The Global City: New York, London, Tokyo, 2nd edn. Princeton, NJ: Princeton University Press.
SorEnson, D.J. (1997), An Empirical Evaluation of the Profit Cycle Theory. Journal of Regional Science 37, pp. 275-305.

Thompson, W.R. (1968), Internal and External Factors in Urban Economies. In: H.S. PERLOFF \& L. WINGO, eds, Issues in Urban Economics, pp. 43-62. Baltimore, MD: Johns Hopkins University Press and Resources for the Future.

UtTerback, J.M. \& W.J. Abernathy (1975), A Dynamic Model of Product and Process Innovation. Omega 3, pp. 639-656.

UtTerback, J.M. \& F.F. SuAREZ (1993), Innovation, Competition, and Industry Structure. Research Policy 22, pp. 1-21.

VAN OORT, F.G. (2004), Urban Growth and Innovation. Spatially Bounded Externalities in the Netherlands. Aldershot: Ashgate.

VAn OORT, F.G., M. Burger, J. KNOBEn\& O. RASPE (2012), Multilevel Approaches and the Firmagglomeration Ambiguity in Economic Growth Studies. Journal of Economic Surveys 26, pp. 468491.

VERNON, R. (1966), International Investment and International Trade in the Product Cycle. Quarterly Journal of Economics 80, pp. 190-207.

Weterings, A. \& J. KnOBen (2013), Footloose: An Analysis of the Drivers of Firm Relocations over Different Distances. Papers in Regional Science 92, pp. 791-809. 